\title{
The South American opossum, Didelphis marsupialis, from Brazil as another definitive host for Sarcocystis speeri Dubey and Lindsay, 1999
}

\author{
J. P. DUBEY ${ }^{1 *}$, C. E. KERBER ${ }^{2}$, D. S. LINDSAY ${ }^{3}$, N. KASAI ${ }^{4}$ and H. F. J. PENA ${ }^{4}$ \\ ${ }^{1}$ United States Department of Agriculture, Agricultural Research Service, Livestock and Poultry Sciences Institute, \\ Parasite Biology and Epidemiology Laboratory, Beltsville, Maryland, 20705-2350, USA \\ ${ }^{2}$ Paddock Laboratórie de Análises, Clínicas Veterinárias, Rua Pero Leão, 149-CEP 05423-060, São Paulo, \\ Brazil \\ ${ }^{3}$ Center for Molecular Medicine and Infectious Diseases, Department of Biomedical Sciences and Pathobiology, \\ Virginia-Maryland Regional College of Veterinary Medicine, Virginia Tech, 1410 Prices Fork Road, Blacksburg, \\ $V A$ 24061-0342, USA \\ ${ }^{4}$ Faculdade de Medicina Veterinaria e Zootechnia da Universidade de São Paulo. AV. Prof. Dr. Orlando Marques de \\ Paivá, 87, CEP 05508-000, São Paulo, Brazil
}

(Received 14 February 2000; revised 8 Fune 2000; accepted 19 Fune 2000)

\section{S U M M ARY}

The North American opossum, Didelphis virginiana, is a definitive host for at least 3 species of Sarcocystis : S. falcatula Stiles 1983, S. neurona Dubey, Davis, Speer, Bowman, de Lahunta, Granstrom, Topper, Hamir, Cummings, Suter 1991, and S. speeri Dubey and Lindsay 1999. In order to identify species of Sarcocystis in the South American opossum, D. marsupialis, Sarcocystis sporocysts from the intestines of a naturally infected opossum (D. marsupialis) from Brazil were fed to 4 gamma-interferon knockout (KO) mice, a nude mouse, and 2 budgerigars (Melopsittacus undulatus). All 4 KO mice became ill and 1 died 42 days post-feeding (p.f.) of sporocysts, 1 was killed 44 days p.f. because of neurological signs, and 2 were killed 52 and 53 days p.f. because of abnormal gaits. Numerous sarcocysts were seen in the skeletal muscles of all $4 \mathrm{KO}$ mice and they were structurally identical to $S$. speeri seen in KO mice fed sporocysts from $D$. virginiana from the United States and D. albiventris from Argentina. The nude mouse was killed 41 days p.f. because it appeared weak; schizonts were seen in sections of its liver and sarcocysts were seen in sections of skeletal muscles. Sarcocystis speeri was cultured in bovine turbinate cells inoculated with liver homogenate from this mouse. Sarcocystis neurona was not demonstrable in tissues of mice. The two budgerigars remained asymptomatic and $S$. falcatula was not found in their tissues when they were killed 29 days p.i. This is the first report of S. speeri from D. marsupialis.

Key words: Sarcocystis speeri, sporocysts, schizonts, Didelphis marsupialis, opossum.

\section{INTRODUCTION}

The North American opossum (Didelphis virginiana) is a definitive host for at least 3 pathogenic species of Sarcocystis; S. falcatula (Box, Meier \& Smith, 1984), S. neurona (Fenger et al. 1997; Dubey \& Lindsay, 1998), and S. speeri (Dubey \& Lindsay, 1999). The sporocysts of these 3 species are similar morphologically, but can be distinguished by their pathogenicity and infectivity to birds and immunodeficient mice, e.g. S. falcatula is not infective for mice, whereas $S$. neurona and $S$. speeri are not infectious for birds and S. falcatula is infective to birds (Marsh et al. 1997; Dubey \& Lindsay, 1998; Dubey, Speer \& Lindsay, 1998). Both S. neurona

* Corresponding author: United States Department of Agriculture, Agricultural Research Service, Livestock and Poultry Sciences Institute, Parasite Biology and Epidemiology Laboratory, Beltsville, Maryland, 20705-2350, USA. Tel: +301504 8128. Fax: + 3015049222.

E-mail: jdubey@1psi.barc.usda.gov and $S$. speeri can induce encephalitis in mice associated with schizonts and merozoites (Dubey \& Lindsay, 1999). Sarcocysts of S. neurona have not been detected in mice to date. However, sarcocysts were seen in gamma interferon knockout (KO) mice fed sporocysts of S. speeri (Dubey et al. 1998; Dubey \& Lindsay, 1999). Recently, S. speeri and S. falcatula were reported from the South American opossum, D. albiventris, from Argentina (Dubey et al. 1999b, $2000 a-d)$. We report D. marsupialis from Brazil as another definitive host for S. speeri.

\section{MATERIALS AND METHODS}

Sarcocystis sporocysts were obtained from an adult D. marsupialis submitted to the University of São Paulo, Brazil as part of a study of the Sarcocystis species observed in opossums in South America. The intestine was removed, the epithelium scraped from the small intestine in to a blender, homogenized and digested in $10 \%$ commercial bleach solution for 
Table 1. Sarcocystis speeri infections in mice fed sporocysts from an opossum, Didelphis marsupialis

\begin{tabular}{lllll}
\hline \hline Mouse type & Day p.i.* & Schizonts $\uparrow$ & Sarcocysts $\uparrow$ & Bradyzoites \\
\hline KO 5880 & Died 42 & Brain & SKM, H, T & Not done \\
KO 5881 & Killed 53 & Not seen & SKM, H, T, O & Yes \\
KO 1248 & Killed 52 & Brain & SKM, H, T, O & Yes \\
KO 1249 & Killed 44 & Brain & SKM, T, O & Not done \\
Nude 6540 & Killed 41 & Liver & SKM & Not done \\
C57/Black & Killed 61 & Not done & Not done & Negative \\
C57/Black & Killed 61 & Not done & Not done & Negative \\
\hline \hline
\end{tabular}

* Day post-inoculation.

$\uparrow$ Results based on examination of tissue sections. H, heart; SKM, skeletal muscle; O, ocular muscles; T, tongue.

$\ddagger$ Results based on acid-pepsin digestion.

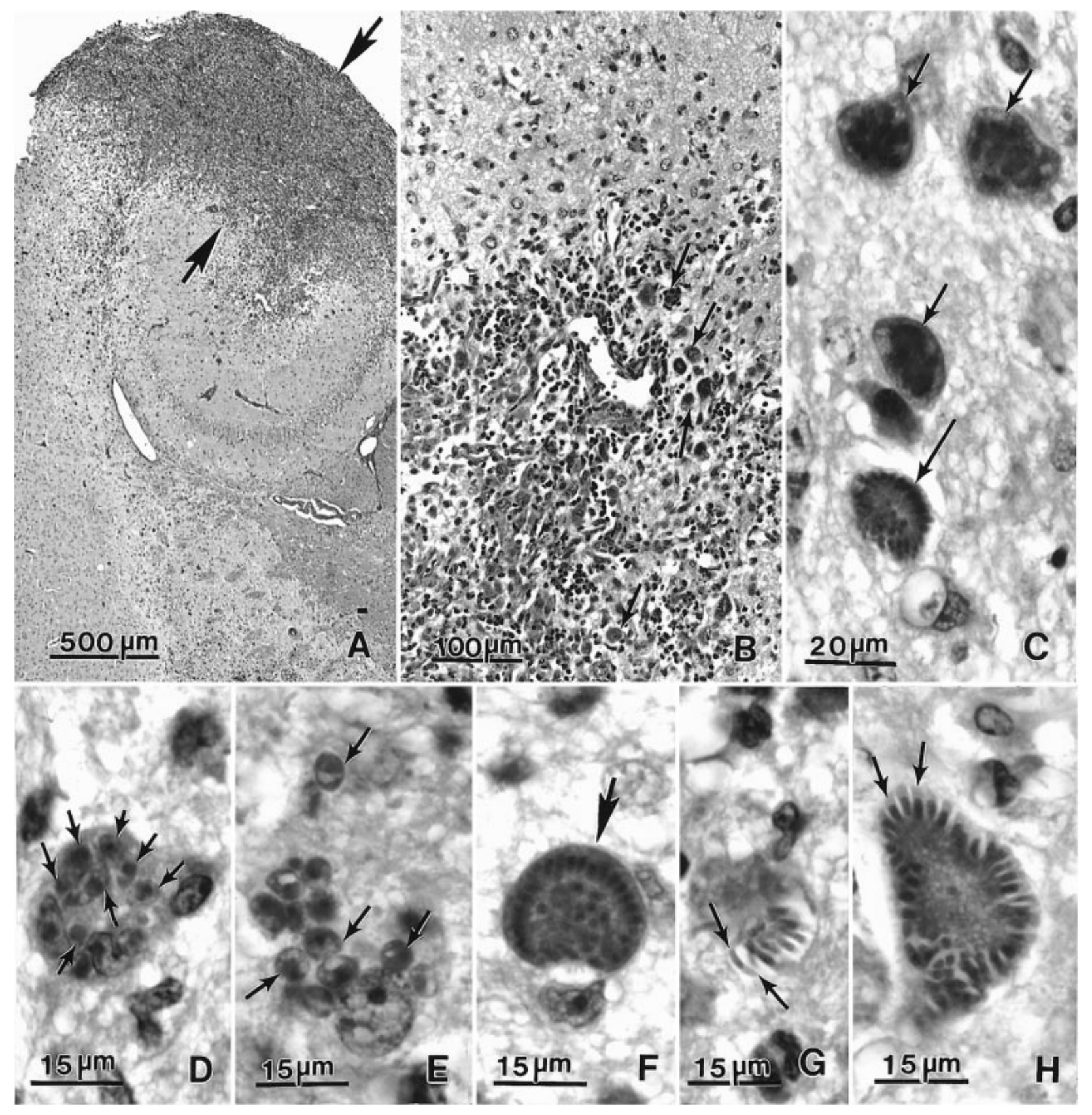

Fig. 1. For legend see opposite. 

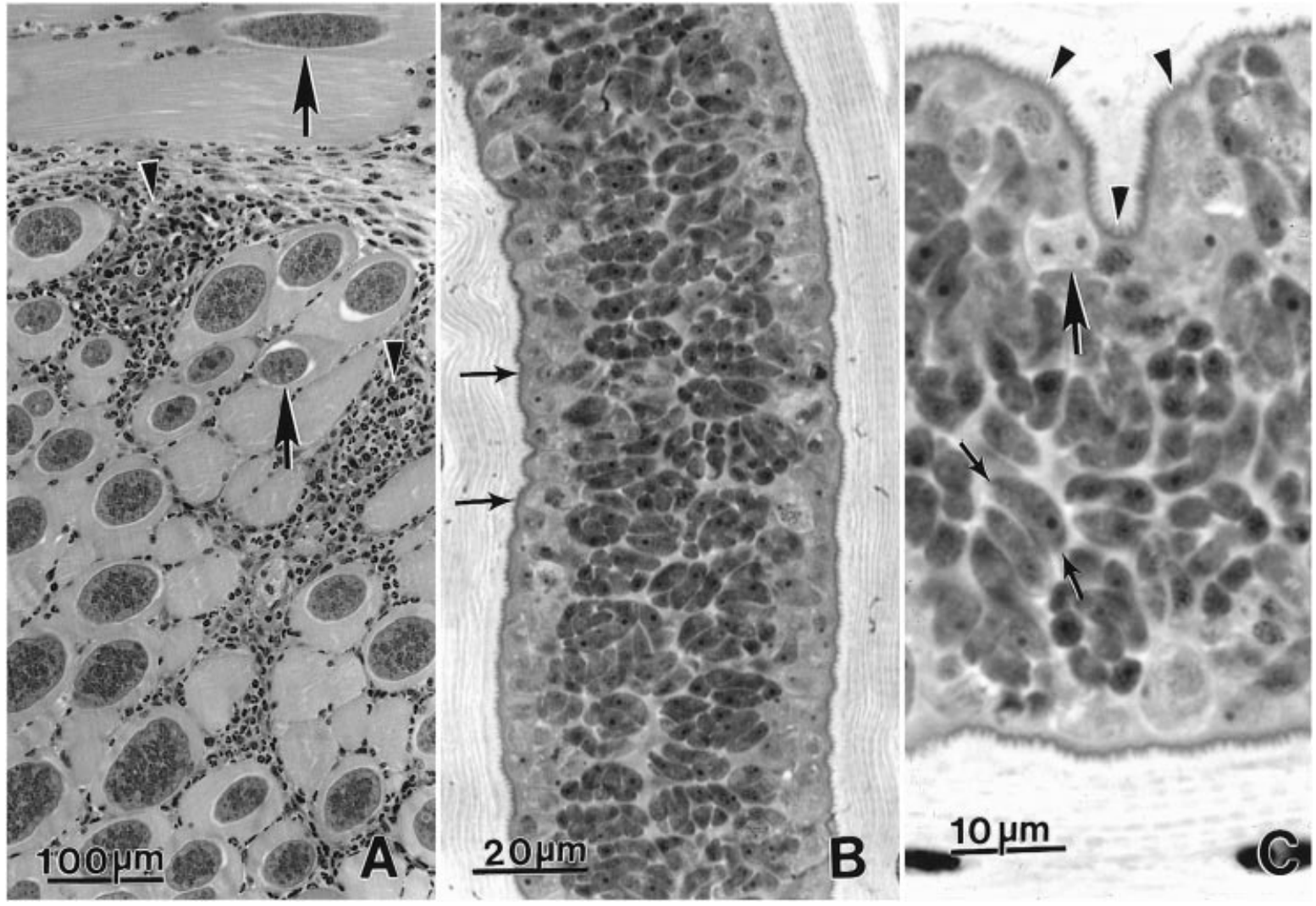

Fig. 2. Sarcocysts in sections of skeletal muscle of a KO mouse 53 days post-feeding of sporocysts from the opossum from Brazil. Haematoxylin and eosin stain. (A) Numerous sarcocysts (arrows) and focal inflammation (arrowheads) in abdominal muscle. (B) Longitudinal section of a sarcocyst. Note thin cyst wall (arrows). (C) Higher magnification of a sarcocyst showing cyst wall with villar protrusions (arrowheads), metrocytes (large arrow), and bradyzoites (small arrows).

10 min. After centrifugations to remove the bleach, the suspension was filtered through a series of metallic sieves (final exclusion $400 \mu \mathrm{m}$ ) and the sporocysts and debris concentrated by centrifugation $(\times 400 \mathrm{~g})$. The resulting material was stored in Hanks balanced salt solution (HBSS) containing $10 \mathrm{mg} / \mathrm{ml}$ streptomycin, $10000 \mathrm{U} / \mathrm{ml}$ penicillin, $500 \mathrm{U} / \mathrm{ml}$ myostatin, and $0.5 \mathrm{mg} / \mathrm{ml}$ fungizone. Sporocysts were shipped via air from São Paulo, Brazil to Beltsville, MD, USA. Sporocysts were stored at $4{ }^{\circ} \mathrm{C}$ until used in the present studies. At Beltsville sporocysts were fed to $4 \mathrm{KO}$ mice (BALB/c-lfng $\left.{ }^{\text {tm1Ts }}\right), 1$ nude $(\mathrm{C} 57 \mathrm{Bl} / 6 \mathrm{JHFH} 11-\mathrm{Nu})$ mouse and $2 \mathrm{C} 57 / \mathrm{Bl}$ mice obtained from Jackson Laboratories (Bar Harbor, ME, USA). Two captive budgerigars (Melopsittacus undulatus) were each fed the same dose of sporocysts fed to mice as described (Dubey \& Lindsay, 1998). The budgerigars were killed 29 days post-feeding (p.f.) sporocysts.

Animals that were killed or died were necropsied. Portions of all internal organs, were fixed in $10 \%$ buffered formalin and processed for histology. Paraffin-embedded sections were cut at $5 \mu \mathrm{m}$ and examined after staining with haematoxylin and eosin. For immunohistochemical staining, paraffin sections were reacted with anti-S. neurona and anti-S. speeri antibodies prepared in rabbits against culturederived merozoites as described (Dubey \& Lindsay, 1998, 1999; Dubey et al. 1999a). Briefly, anti-S. neurona serum was derived from an isolate obtained from a naturally infected opossum no. 8095 (Dubey et al. 1999a). The serum was diluted 1:10000 and it

Fig. 1. Lesions and schizonts of Sarcocystis speeri in the brain of knock-out mice 44 days after feeding sporocysts from Didelphis marsupials from Brazil. Haematoxylin and eosin stain. (A) Severe inflammation (arrows) in the caudal lobe of cerebrum. (B) Higher magnification of the marked area (between arrows) in (A). Note gliosis, formation of new blood vessels, encephalitis and schizonts (arrows). (C) Four schizonts (arrows). (D-H) Schizonts in various stages of development under one magnification. (D) Eight young schizonts (arrows), presumably in one host cell. (E) A group of young schizonts (arrows) with individual nucleus. (F) Schizont with developing merozoites (arrow). (G) Schizont with elongated slender merozoites (arrows). (H) Schizont with thicker merozoites (arrows). 


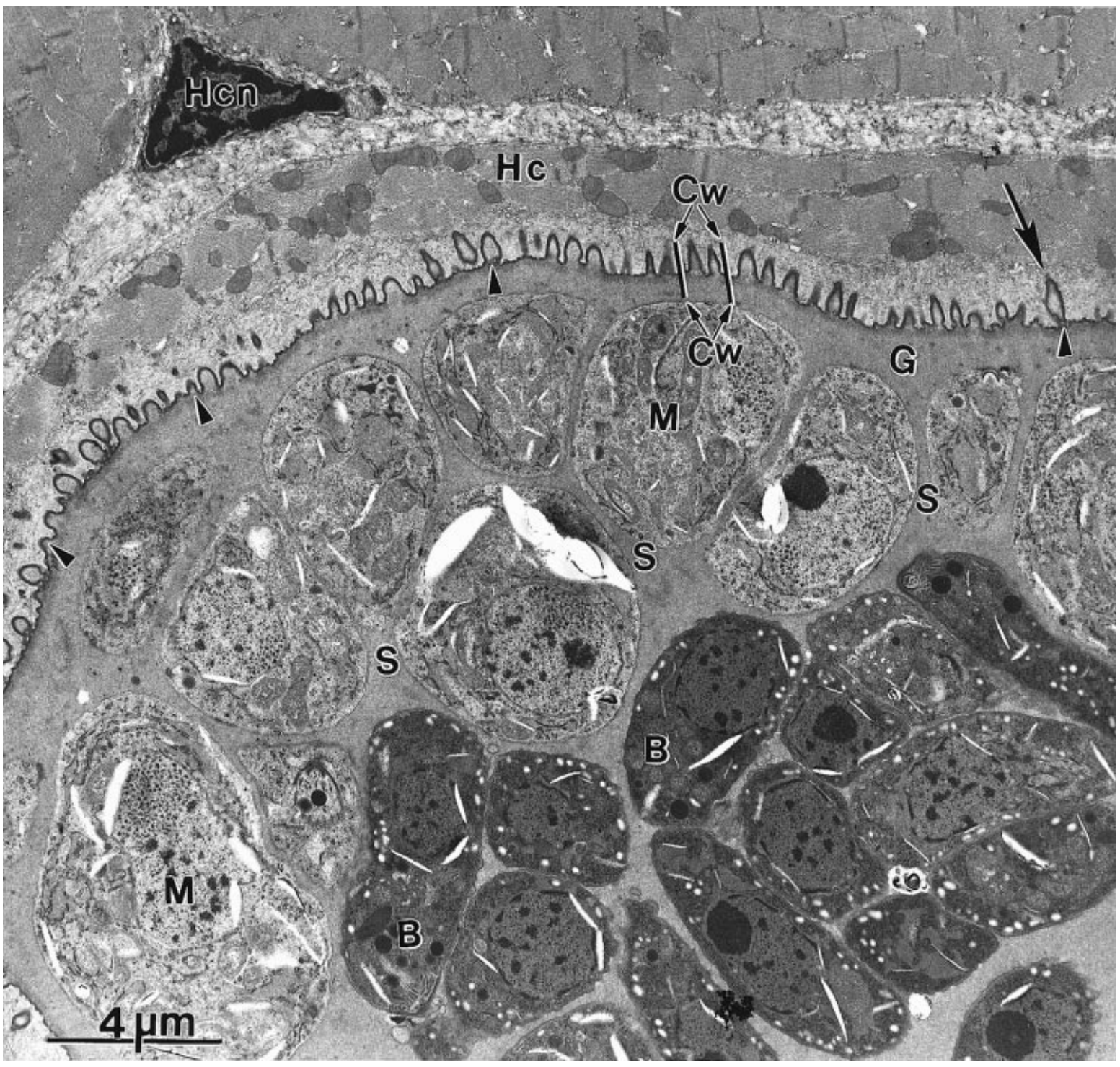

Fig. 3. Transmission electron photomicrograph of Sarcocystis speeri sarcocyst in the skeletal muscle of a KO mouse fed sporocysts from on the cyst wall $(\mathrm{Cw})$ cut at different angles. One of the protrusions (arrow) is steeple-shaped. Also note ground substance $(\mathrm{G})$, metrocytes $(\mathrm{M})$, bradyzoites, $(\mathrm{B})$, septa $(\mathrm{S})$, host cell (Hc), and host cell nucleus (Hen).

does not react with $S$. speeri schizonts and sarcocysts or with any other related apicomplexans (Dubey \& Hamir, 2000). The anti-S. speeri serum was obtained using an isolate from a naturally infected opossum from Argentina (Dubey \& Lindsay, 1999). It was diluted 1:5000 and it does not react with $S$. neurona schizonts.

The carcasses of $\mathrm{KO}$ mice killed 52 and 53 days p.f. and of $\mathrm{C} 57 / \mathrm{Bl}$ mice killed 73 days p.f. were homogenized in a blender, digested in acid pepsin solution, and the digest examined microscopically for Sarcocystis bradyzoites (Dubey, Speer \& Fayer, 1989).

The nude mouse was killed 41 days p.f. Attempts were made to cultivate $S$. speeri from the liver of this mouse. Liver homogenate was inoculated onto bovine turbinate cells (B'T cells, ATCC CRL 1390, American Type Culture collection, Rockville, MD, USA) as described (Dubey et al. 2000 b).

Portions of skeletal muscle from KO mouse 5881 (Table 1) were fixed in $3 \%(\mathrm{v} / \mathrm{v})$ glutaraldehyde in phosphate buffer and later processed for ultrastructural examination at the Center for Molecular Medicine and Infectious Diseases, VirginiaMaryland Regional College of Veterinary Medicine, Virginia Tech, Blacksburg, Virginia, USA. Tissues were post-fixed in $1 \%(\mathrm{w} / \mathrm{v})$ osmium tetroxide, dehydrated in a series of ethanols, passed through 2 changes of propylene oxide, and embedded in Poly/Bed 812 resin (Polysciences Inc., Warrington, PA, USA). Thin sections were stained with uranyl acetate and lead citrate and examined with a JOEL- 
100 CX II transmission electron microscope (TEM) operating at $80 \mathrm{kV}$.

\section{RESULTS}

All 4 KO mice fed sporocysts became ill around 40 days p.f. One mouse died 42 days p.f., and 3 were killed 44, 52, 53 days p.f. because they had neurological signs or had difficulty walking (Table 1). Mice that died or were killed 42 and 52 days p.f. had severe encephalitis associated with numerous schizonts and merozoites. In the mouse killed 52 days p.f., there was a large lesion in the caudal lobe of the cerebrum with necrosis of the neuropil and marked gliosis (Fig. 1A). Myriads of Sarcocystis schizonts in all stages of development were seen (Fig. $1 \mathrm{~B}-\mathrm{H})$. There were groups of young round to ovalshaped small schizonts (Fig. 1D, E) that resembled metrocytes. These groups of schizonts in similar stages of development probably resulted from merozoites from parent schizonts without leaving the host cell. This phenomenon is typical of $S$. falcatula, $S$. neurona and $S$. speeri asexual development in cell culture (Lindsay et al. 1999; Dubey et al. $1999 b, 2000 b$ ).

Sarcocysts were seen in all $4 \mathrm{KO}$ mice. These sarcocysts were thin walled and had characteristic villar protrusions of $S$. speeri (Fig. 2). Numerous sarcocysts were seen in skeletal muscle including tongue, diaphragm, abdomen and ocular muscles. A few sarcocysts were seen in the myocardium. Bradyzoites were seen in pepsin digests of muscles of mice killed 52 and 53 days p.f. Sarcocystis zoites were not seen in muscle digests of the $\mathrm{C} 57 / \mathrm{B} 1$ mice.

Schizonts in various stages of development were seen in cell culture by day 15 post-infection (p.i.). On day 28 p.i. several isolated groups of asexual development were seen. Occasionally, schizonts contained a residual body. The merozoites and schizonts were structurally similar to those of $S$. speeri cultured from the liver of D. albiventris from Argentina (Dubey et al. 2000).

Fourteen sarcocysts were examined using TEM. Metrocytes were the most abundant stage present in sarcocysts. The primary sarcocyst wall consisted of the parasitophorous vacuolar membrane and an underlying electron-dense layer. Villar protections came off the sarcocyst wall and contained only ground substance internally (Fig. 3). The ground substance was also present immediately below the primary sarcocyst wall and divided the sarcocyst into compartments. Bradyzoites were few in number but contained all the organelles typical of this stage.

Schizonts and merozoites in mice reacted positively with anti-S. speer $i$ serum but not with anti-S. neurona serum. Neither schizonts nor sarcocysts were seen in tissues of the two budgerigars.

\section{DISCUSSION}

Schizonts observed in tissues of the $\mathrm{KO}$ and nude mice were structurally similar to those of S. speeri (Dubey \& Lindsay, 1999). The results of the present study indicate the S. speeri occurs naturally in Brazil in D. marsupialis.

Sarcocystis neurona-induced equine protozoal encephalomyelitis (EPM) is a serious neurological disease of horses in North America, Brazil and Panama (Dubey et al. 1991; MacKay, 1997). The distribution of EPM closely parallels the range and distribution of the opossum, D. virginiana. Whether $D$. albiventris and D. marsupialis are also a host for $S$. neurona is unknown. One way to identify the presence of $S$. neurona in opossum faeces is by bioassay in gamma interferon knockout or nude mice (Dubey \& Lindsay, 1998). The results of the present investigation indicate that $D$. marsupialis is another definitive host for $S$. speeri and should be considered when attempting to isolate $S$. neurona sporocysts from opossums in South America.

\section{REFERENCES}

Box, F. D., MEIER, J. L. \& SMiTh, J. H. (1984). Description of Sarcocystis falcatula Stiles, 1893, a parasite of birds and opossums. Fournal of Protozoology 31, 521-524.

DUbey, J. P., DAVIS, S. W., SPEER, C. A., BOWMAN, D. D., DE LAHUNTA, A., GRANSTROM, D. E., TOPPER, M. J., HAMIR, A. N., CUMmings, J. F. \& SUTER, M. M. (1991).

Sarcocystis neurona n. sp. (Protozoa: Aplcomplexa), the etiologic agent of equine protozoal myeloencephalitis. Fournal of Parasitology 77, 212-218.

DUBEY, J. P. \& HAMIR, A. (2000). Immunohistochemical confirmation of Sarcocystis neurona infections in raccoons, mink, cat, skunk and pony. Fournal of Parasitology (in the Press).

DUBEY, J. P. \& LINDSAY, D. S. (1998). Isolation in immunodeficient mice of Sarcocystis neurona from opossum (Didelphis virginiana) feces, and its differentiation from Sarcocystis falcatula. International Fournal for Parasitology 28, 1823-1828.

DUbEy, J. P. \& LINDSAY, D. S. (1999). Sarcocystis speeri $\mathrm{n}$. sp. (Protozoa: Sarcocystidae) from the opossum (Didelphis virginiana). Fournal of Parasitology 85, 903-909.

DUbey, J. P., LINDSAY, D. S., REZENDE, P. C. B. \& COSTA, A. J. $(2000 a)$. Characterization of a new Sarcocystis falcatula-like parasite from the South American opossum, Didelphis albiventris from Brazil. Fournal of Eukaryotic Microbiology (in the Press).

DUBEY, J. P., MATTSON, D. E., SPEER, C. A., BAKER, R. J., MUlRoONEY, D. M., TORNQUisT, S. J., HAMIR, A. N. \& GERros, T. C. (1999a). Characterization of Sarcocystis neurona isolate (SN6) from a naturally infected horse from Oregon. Fournal of Eukaryotic Microbiology 46, $500-506$.

Dubey, J. P., SPEER, C. A. \& FAYER, R. (1989). Sarcocystosis of Animals and Man. CRC Press. Boca Raton, Florida. 
DUBEY, J. P., SPEER, C. A. \& LINDSAY, D. S. (1998). Isolation of a third species of Sarcocystis in immunodeficient mice fed feces from opossums (Didelphis virginiana) and its differentiation from Sarcocystis falcatula and Sarcocystis neurona. Fournal of Parasitology 84, 1158-1164.

DUbEy, J. P., SPEER, C. A. \& LINDSAY, D. S. (2000 b). In vitro cultivation of schizonts of Sarcocystis speeri Dubey and Lindsay, 1999. Fournal of Parasitology 86, 671-678.

Dubey, J. P., SPEER, C. A., BOWMAN, D. D., HORTON, K. M., VENTURini, C. \& VENTURINi, L. $(2000 d)$. Experimental transmission of Sarcocystis speeri from the South American opossum (Didelphis albiventris) to the North American opossum (Didelphis virginiana). Fournal of Parasitology 86, 624-627.

Dubey, J. P., venturini, L., venturini, M. C. \& SPEer, C. A. $(2000 c)$. Isolation of Sarcocystis speeri Dubey and Lindsay, 1999 from the South American opossum (Didelphis albiventris) from Argentina. Fournal of Parasitology 86, 160-163.

Dubey, J. P., Venturini, L., venturini, C., Basso, W. \& UNZAGA, J. (1999b). Isolation of Sarcocystis falcatula from the South American opossum (Didelphis albiventris) from Argentina. Veterinary Parasitology 86, 239-244.

Fenger, C. K., GRanstrom, D. E., Gajadhar, A. A., Williams, N. M., MCCRILlis, S. A., STAMPER, S., LANGEMEIER, J. L. \& DUBEY, J. P. (1997). Experimental induction of equine protozoal myeloencephalitis in horses using Sarcocystis sp. sporocysts from the opossum (Didelphis virginiana). Veterinary Parasitology 68, 199-213.

LINDSAY, D. S., DUBEY, J. P., HORTON, K. M. \& BOWMAN, D. D. (1999). Development of Sarcocystis falcatula in cell cultures demonstrates that it is different from Sarcocystis neurona. Parasitology 118, 227-233. MackAY, R. J. (1997). Equine protozoal myeloencephalitis. Veterinary Clinics of North America: Equine Practice 13, 79-96.

MARSH, A. E., BARR, B. C., TELL, L., KOSKI, M., GREINER, E., DAME, J. \& CONRAD, P. A. (1997). In vitro cultivation and experimental inoculation of Sarcocystis falcatula and Sarcocystis neurona merozoites into budgerigars (Melopsittacus undulatus). Fournal of Parasitology 83, 1189-1192. 